\title{
Chemical Constituents from Salvia fruticosa libanotica
}

\author{
Rima Boukhary ${ }^{*}$, Maha Aboul-Ela ${ }^{1}$, Othman Al-Hanbali ${ }^{2}$ and Abdalla El-Lakany ${ }^{1}$
}

\section{Rima Boukhary ${ }^{1 *}$, Maha Aboul-Ela ${ }^{1}$, Othman Al- Hanbali ${ }^{2}$ and Abdalla El-Lakany ${ }^{1}$}

\section{${ }^{1}$ Department of Pharmaceutical Sciences, Faculty of Pharmacy, Beirut Arab University, 115020, Beirut, LEBANON. \\ ${ }^{2}$ Faculty of Pharmacy, AL-Zaytoonah University, 11733, Amman, JORDAN. \\ Correspondence \\ Rima Boukhary}

Department of Pharmaceutical Sciences, Faculty of Pharmacy, Beirut Arab University, 115020, Beirut, LEBANON.

Phone no: +96103334970

E-mail: boukharyrima@yahoo.com

\section{History}

- Submission Date: 03-08-2017;

- Review completed: 11-08-2017;

- Accepted Date: 20-11-2017

DOI : 10.5530/pj.2018.1.9

Article Available online http://www.phcogj.com/v10/i1

\section{Copyright}

(C) 2018 Phcog.Net. This is an openaccess article distributed under the terms of the Creative Commons Attribution 4.0 International license.

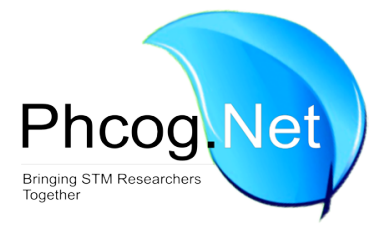

\begin{abstract}
Objective: Plants of genus Salvia are used in traditional folk medicine for their antidiabetic, anti-oxidant effects and for gastric disorders. The oil has an antiseptic property and it is used as a fragrance in soaps and perfumes. An infusion of the leaves is widely used as a mouthwash or gargle and for the treatment of inflammation of the mouth and throat. It is used as carminative, antiinflammatory, astringent, cytotoxic and antispasmodic. Materials and Methods: Air-dried powdered aerial parts and roots of Salvia fruticosa libanotica were extracted separately with ethanol and acetone then their residues were separately extracted with different solvents on silica gel columns. Results: From Salvia fruticosa libanotica, eight phenolic compounds were isolated from methylene chloride, ethyl acetate and butanol extracts of the chosen plant. The chemical structures of the isolated compounds were determined by NMR, MS, IR and UV spectroscopic methods. Conclusion: Among these compounds three Flavonoids named apigenin, luteolin and rutin were identified in addition to three phenolic acids which are ferulic acid, gallic acid and rosemarinic acid from aerial parts. Moreover, carnosol and dehydro-abietic acid were also isolated from Salvia fruticosa libanotica root extract. All the isolated compounds were obtained for the first time from Salvia fruticosa libanotica.

Keywords: Salvia fruticosa libanotica, Antidiabetic, Anti-oxidant, Rutin; Carnosol, Dehydroabietic acid.
\end{abstract}

\section{INTRODUCTION}

Salvia constitutes the largest genus of the Family Lamiaceae with about 900 species. Plants of genus Salvia are ever green shrubs present all over the world and some species largely reputed in folk medicine because they are used as spices in food industry and flavoring agents in cosmetics and aromatherapy. ${ }^{1,2}$ Pharmacological and phytochemical studies showed that salvia species are considered "cure-all" type plants. ${ }^{3,4}$ Salvia aegyptiaca $\mathrm{L}$ is used in cosmetics, gonorrhea, hemorrhoids, eye diseases and as antispasmodic. ${ }^{5,6}$ Salvia hispanica reduces blood sugar level and is a novel agent in the prevention and treatment of cardiovascular diseases. $^{7}$ Salvia officinalis known as Sage is effective in Alzheimer disease. ${ }^{8}$ The essential oil infusion and tinctures of salvia plants are used worldwide in traditional medicine such anti-inflammatory, antioxidant, for oral cavity inflammation, for tonsillitis and for certain gastric diseases. ${ }^{9,10,11}$ In 2000, Wang reported that, Salvia was always as the top of the list of house hold remedies for the relief of itching and lowering of fevers and relief of nervous headache. The leaves and roots of salvia are very popular for their antioxidative, anti-inflammatory and hypoglycemic properties due to the radical scavenging activity of their polyphenolics contents such as carnosic acid, carnosol, rosmarinic acid and flavonoids. ${ }^{12,13,14}$ These phenolic compounds alleviated hyperalgesia in pain conditions in rats. ${ }^{15}$
S. fruticosa libanotica is an indigenous plant growing wild in Lebanon with an antioxidant potential.,10 Therefore, this research aims to isolate the antioxidative phenolic constituents including flavonoids and abietane diterpenoids from both aerial and root parts that might have biological activities.

\section{MATERIALS AND METHODS}

General

The IR spectra were determined on Shimadzu IR spectrophotometer (FT/IR-8300) in $\mathrm{KBr}$ discs and the absorption bands were measured in $\mathrm{cm}^{-1}$. The ${ }^{1} \mathrm{HNMR}$ and ${ }^{13} \mathrm{CNMR}$ spectra were recorded on Bruker Avance 500MHZ apparatus. Column chromatography was performed over silica gel (70-230, mesh, Fluka) using petroleum ether, methylene chloride, ethyl acetate and methanol gradients as eluents. UV spectra were determined using CibaCorning Double-beam spectrophotometer (2800 spectroscan) and mass spectra were recorded on a AEIMS-50 spectrometer.

\section{Plant material}

Fresh Salvia libanotica fruticosa was collected at the flowering stage from the littoral of Beirut in March and April 2011. The plant was identified by prof. Dr. Georges Tohme former professor of Taxonomy. A dried specimen (No.PS.14.12) was kept in the 
Faculty of Pharmacy. The plant was dried under shade at $25^{\circ} \mathrm{C}$ and the dried aerial parts and roots were grinded separately with a blender.

\section{Extraction and Isolation}

Air-dried powdered aerial parts of Salvia fruticosa libanotica (4.5 kg) were separately extracted with $95 \%$ ethanol at room temperature for 3 weeks. The combined alcoholic extract was then concentrated under reduced pressure to complete dryness giving $105.6 \mathrm{~g}$ of dry extract. The residue was successively extracted with light petroleum ether, methylene chloride, ethyl acetate, $\mathrm{n}$-butanol and methanol. The methylene chloride extract was evaporated in vacuum to give $29.5 \mathrm{~g}$ of residue that was subjected to column chromatography (CC) on silica gel and eluted with chloroform-methanol as eluent with increasing methanol content to provide 62 fractions.

Fractions 19-25 (1.75g) were combined subjected to PTLC on fluorescent silica gel plates using solvent system Chloroform: Ethyl acetate (6:4) giving two zones. Both zones were scrapped off and eluted with methanol and the solvent was distilled off. Crystallization of the obtained residues from methanol yielded $16 \mathrm{mg}$ of yellowish crystals, m.p. $345^{\circ} \mathrm{C}$, designated as material 1 and $18 \mathrm{mg}$ of yellow crystals, m.p. $320^{\circ} \mathrm{C}$ designated as material 2. Moreover, the ethyl acetate extract $15 \mathrm{~g}$ was dissolved in methanol with slight warming. A dark yellow residue was formed up on cooling. The deposit was separated and crystallized from methanol to give $250 \mathrm{mg}$ of yellowish crystals $\mathrm{R}_{\mathrm{f}}$ value 0.8 system Chloroform-Methanol (3:5) m.p. $242^{\circ} \mathrm{C}$ named as material 3.

$1.5 \mathrm{~kg}$ of air-dried powdered roots of Salvia fruticosa libanotica were extracted in a soxhelet apparatus with acetone. The combined acetone extract was evaporated under pressure giving $17 \mathrm{~g}$ dark brown residue that was subjected to (CC) on silica gel and eluted with Hexane-Ethyl acetate as eluent with increasing ethyl acetate content. A total of 47 fractions were collected and concentrated to dryness under reduced pressure. Fractions $20-26$ gave $0.84 \mathrm{~g}$ of shiny white crystals named as material 4. While Fractions 33-39 showed one major spot with an $\mathrm{R}_{\mathrm{f}}$ value 0.64 system Chloroform-Methanol (9:1) acquiring a yellow color when exposed to ammonia vapor. The residue left after evaporation of the solvent was purified by PTLC fluorescent silica gel using the same system. Then the dark zone was scrapped off after visualization and eluted with methanol. The solvent was distilled off. Repeated crystallization from methanol afforded $200 \mathrm{mg}$ of white crystalline powder m.p. $172-175^{\circ} \mathrm{C}$ designated as material $\mathbf{5 .}$

Apigenin (1): yellowish crystals, m.p. $345^{\circ} \mathrm{C}$. UV $\left(\lambda_{\max }, \mathrm{MEOH}\right): 350,265$ $\mathrm{nm}$. Degradation takes place with all used shifts reagents. EIMS $\mathrm{m} / \mathrm{z}$ (rel. abund. \%): 270 (14) $\left[\mathrm{M}^{+}, \mathrm{C}_{15} \mathrm{H}_{10} \mathrm{O}_{5}\right], 253$ (80), 259 (49), 249 (38). IR (KBr, $v_{\max }, \mathrm{cm}^{-1}$ ) 3640, 3400,1710,1663 $\mathrm{cm}^{-1} .{ }^{1} \mathrm{HNMR}$ (DMSO, $500 \mathrm{MHz}$ ); d 6.7 (1H, S, H-3), 6.19 (1H, d, J=2 Hz, H-6 ), 6.25 (1H, d, J=2 Hz, H-8), 7.9 $\left(1 \mathrm{H}, \mathrm{dd}, \mathrm{J}=8,2 \mathrm{~Hz}, \mathrm{H}-2^{\prime}\right), 6.93\left(1 \mathrm{H}, \mathrm{dd}, \mathrm{J}=8,2 \mathrm{~Hz}, \mathrm{H}-3^{\prime}\right), 6.93(1 \mathrm{H}, \mathrm{dd}$, $\left.\mathrm{J}=8,2 \mathrm{~Hz}, \mathrm{H}-5^{\prime}\right), 7.9\left(1 \mathrm{H}, \mathrm{dd}, \mathrm{J}=8,2 \mathrm{~Hz}, \mathrm{H}-6^{\prime}\right)$.

Luteolin (2): Dark yellow crystals, m.p. $320^{\circ} \mathrm{C}$. UV $\left(\lambda_{\max }, \mathrm{MeOH}\right): 350$, $250 \mathrm{~nm},(\mathrm{MeOH}+\mathrm{NaOMe}): 390,273 \mathrm{~nm},\left(\mathrm{MeOH}+\mathrm{AlCl}_{3}\right): 388,270$ $\mathrm{nm},\left(\mathrm{MeOH}+\mathrm{AlCl}_{3}+\mathrm{HCl}\right): 388,270 \mathrm{~nm},(\mathrm{MeOH}+\mathrm{NaOAc}): 385,275$ nm. EIMS m/z (rel.abund.\%): $286(98)\left[\mathrm{M}^{+}, \mathrm{C}_{15} \mathrm{H}_{11} \mathrm{O}_{6}\right], 259$ (40), 241 (17), 153 (97), 135 (23). IR (KBr, $\left.v_{\max }, \mathrm{cm}^{-1}\right) 3375,1657,1610,1125 .{ }^{1} \mathrm{HNMR}$ (DMSO, $500 \mathrm{MHz}$ ), integrated for 11 protons: d $6.6(1 \mathrm{H}, \mathrm{s}, \mathrm{H}-3), 6.23$ (1H, br, s, H-6), 6.48 (1H, br, s, H-8), $7.4(1 \mathrm{H}, \mathrm{d}, \mathrm{J}=2.1 \mathrm{~Hz}, \mathrm{H}-2$ '), 6.85 $\left(1 \mathrm{H}, \mathrm{d}, \mathrm{J}=8.2 \mathrm{~Hz}, \mathrm{H}-5^{\prime}\right)$ and $7.45\left(1 \mathrm{H}, \mathrm{dd}, \mathrm{J}=8.2 \mathrm{~Hz}, \mathrm{H}-6^{\prime}\right)$.

Rutin (3): yellow crystals, m.p. $242^{\circ} \mathrm{C} \cdot \mathrm{UV}\left(\lambda_{\max }, \mathrm{MEOH}\right): 215,250$, $350 \mathrm{~nm},(\mathrm{MeOH}+\mathrm{NaOMe}): 395,270 \mathrm{~nm},\left(\mathrm{MeOH}+\mathrm{AlCl}_{3}\right): 355,290$, $\left(\mathrm{MeOH}+\mathrm{AlCl}_{3}+\mathrm{HCl}\right): 355,291,(\mathrm{MeOH}+\mathrm{NaOAc}): 374,260 . \mathrm{IR}(\mathrm{KBr}$, $\left.v_{\max }, \mathrm{cm}^{-1}\right) 3400,1650,1450,1050$. EIMS m/z (rel.abund.\%): 611(54) $\left[\left(\mathrm{M}^{+}+1\right), \mathrm{C}_{27} \mathrm{H}_{30} \mathrm{O}_{16}\right] ; 465$ (15); 303 (20). ${ }^{1} \mathrm{HNMR}$ (DMSO, $500 \mathrm{MHz}$ );
$6.25(1 \mathrm{H}, \mathrm{d}, \mathrm{J}=2 \mathrm{~Hz}, \mathrm{H}-6), 6.4(1 \mathrm{H}, \mathrm{d}, \mathrm{J}=2 \mathrm{~Hz}, \mathrm{H}-8), 7.6(1 \mathrm{H}, \mathrm{s}, \mathrm{H}-2$ '), $6.82(1 \mathrm{H}, \mathrm{d}, \mathrm{J}=8 \mathrm{~Hz}, \mathrm{H}-5$ '), $7.52(1 \mathrm{H}, \mathrm{dd}, \mathrm{J}=8.2 \mathrm{~Hz}, 2 \mathrm{~Hz}, \mathrm{H}-6$ '), $5.15(1 \mathrm{H}$, $\mathrm{d}, \mathrm{J}=2 \mathrm{~Hz}, 1 \mathrm{H}$-sugar $), 4.54(4 \mathrm{H}, \mathrm{d}, \mathrm{J}=8 \mathrm{~Hz}, \mathrm{H}-1-\mathrm{Gluc})$ and $3.82(1 \mathrm{H}, \mathrm{d}$, $\mathrm{J}=1 \mathrm{~Hz}, 1 \mathrm{H}-\mathrm{Rhamn}$ ). ${ }^{13} \mathrm{CNMR}$ (DMSO,500 MHz); 158.5 (C-2), 134 (C-3), 178 (C-4), 162.5 (C-5), 101.5 (C-6), 164 (C-7), 93.8 (C-8), 123.1 (C-1'), 117.5 (C-2'), 144 (C-3'), 148.5 (C-4'), 116.5 (C-5') and 123.5 (C-6').

Carnosol (4): white crystals, m.p. $210-220^{\circ} \mathrm{C}$. UV ( $\left.\lambda_{\max }, \mathrm{MEOH}\right): 310$, $382 \mathrm{~nm}$. IR (KBr, $v_{\max }, \mathrm{cm}^{-1}$ ) 3320,1700,1600,1060. EIMS m/z (rel. abund.\%): 330 (100) $\left[\mathrm{M}^{+}, \mathrm{C}_{20} \mathrm{H}_{26} \mathrm{O}_{4}\right], 301$ (17), 285 (53), 259 (7). IR ( $\mathrm{KBr}$, $\left.v_{\mathrm{m}}, \mathrm{cm}^{-1}\right) 3320,1700,1600,1060 .{ }^{1} \mathrm{HNMR}(\mathrm{DMSO}, 500 \mathrm{MHz}) ; \mathrm{d} 2.65(2 \mathrm{H}$, triplet, $\left.\mathrm{J}=7 \mathrm{~Hz}, \mathrm{CH}_{2}-1\right), 2.09\left(2 \mathrm{H}\right.$, quintet, $\left.\mathrm{J}=7 \mathrm{~Hz}, \mathrm{CH}_{2}-2\right), 1.25(2 \mathrm{H}, \mathrm{m}$, $\left.\mathrm{J}=7 \mathrm{~Hz}, \mathrm{CH}_{2}-3\right), 6.67(1 \mathrm{H}, \mathrm{s}, \mathrm{H}-14), 5.47(1 \mathrm{H}, \mathrm{d}, \mathrm{J}=2 \mathrm{~Hz}, \mathrm{H}-7), 3.2(1 \mathrm{H}$, heptet, J=7Hz, H-15), $1.14\left(3 \mathrm{H}, \mathrm{d}, \mathrm{J}=7 \mathrm{~Hz}, \mathrm{CH}_{3}-16, \mathrm{CH}_{3}-17\right) .{ }^{13} \mathrm{CNMR}$ (DMSO, $500 \mathrm{MHz}$ ); 29.7 (C-1), 19.9 (C-2), 41 (C-3), 31.5 (C-4), 45.4 (C-5), 29.6 (C-6), 77.4 (C-7), 132.5 (C-8), 122.3 (C-9), 48.3 (C-10), 143.5 (C-11), 144 (C-12), 134 (C-13), 116 (C-14), 26.6 (C-15), 23.1 (C-16), 23.2 (C-17), 19.7 (C-18), 31.7 (C-19) and 175.95 (C-20).

Dehydro-abietic acid (5): white crystals, m.p.172-175 ${ }^{\circ} \mathrm{C}$. UV $(\lambda \max$, $\mathrm{MEOH}$ ): 568, 425nm. EIMS m/z (rel.abund.\%): [ $\left.\mathrm{M}^{+}+1\right]$; 301, 279 (25); 252 (78); 211 (39). IR (KBr. $v_{\max }, \mathrm{cm}^{-1}$ ) 3330, 1705,1610. ${ }^{1} \mathrm{HNMR}$ (DMSO, $500 \mathrm{MHz}) ; 2.18\left(2 \mathrm{H}, \mathrm{m}, \mathrm{CH}_{2}-1\right), 1.67\left(2 \mathrm{H}\right.$, quartet, J=7 Hz, $\left.\mathrm{CH}_{2}-2\right)$, $2\left(2 \mathrm{H}, \mathrm{m}, \mathrm{CH}_{2}-3\right), 1.4(1 \mathrm{H}$, triplet, $\mathrm{J}=7 \mathrm{~Hz}, \mathrm{H}-5), 1.67(2 \mathrm{H}$, quartet, $\left.\mathrm{J}=7 \mathrm{~Hz}, \mathrm{CH}_{2}-6\right), 2.37\left(2 \mathrm{H}\right.$, triplet, $\left.\mathrm{J}=7 \mathrm{~Hz}, \mathrm{CH}_{2}-7\right), 7.17(1 \mathrm{H}, \mathrm{d}, \mathrm{J}=9 \mathrm{~Hz}$, $\mathrm{H}-11), 7(1 \mathrm{H}, \mathrm{d}, \mathrm{J}=9 \mathrm{~Hz}, \mathrm{H}-12)$ and 1.17 (6H,d, H-16, H-17). ${ }^{13} \mathrm{CNMR}$ (DMSO, 500 MHz); 40.57 (C-1), 18.6 (C-2), 36.7 (C-3), 45.1 (C-4), 46.8 (C-5), 21.58 (C-6), 29.9 (C-7), 134.5 (C-8), 147.2 (C-9), 38.2 (C-10), 124.5 (C-11), 124.1 (C-12), 145.5 (C-13), 126.9 (C-14), 33.3 (C-15), 24.4 (C-16 and C-17), 16.8 (C-19) and 25.2 (C-20).

\section{RESULTS AND DISCUSSION}

Compounds 1, 2 and 3 were found to be 5-hydroxyflavonol derivatives. Compound 1 was deduced to be $\mathrm{C}_{15} \mathrm{H}_{11} \mathrm{O}_{5}$ and its UV spectra in $\mathrm{AlCl}_{3}$ and $\mathrm{AlCl}_{3} / \mathrm{HCl}$ showed the absence of 3'-OH. EIMS showed its molecular ion peak at $\mathrm{m} / \mathrm{z}=270 .{ }^{1} \mathrm{HNMR}$ was integrated for 11 protons. Accordingly, compound 1 was identified as apigenin. It was confirmed by co-chromatography with apigenin standard. The molecular formula of compound 2 was deduced to be $\mathrm{C}_{15} \mathrm{H}_{11} \mathrm{O}_{6}$ based on different spectral evidence. EIMS showed its molecular ion peak at $\mathrm{m} / \mathrm{z}=286 .{ }^{1} \mathrm{HNMR}$ was integrated for 11 protons. UV absorption at 213,250 , and 350 indicated that it is highly conjugated. Comparison of the different spectral data of compound 2 with published data showed that it is Luteolin. ${ }^{16,17}$ Acid hydrolysis of compound 3 afforded glucose as a sugar part and quercetin (Figure 1).

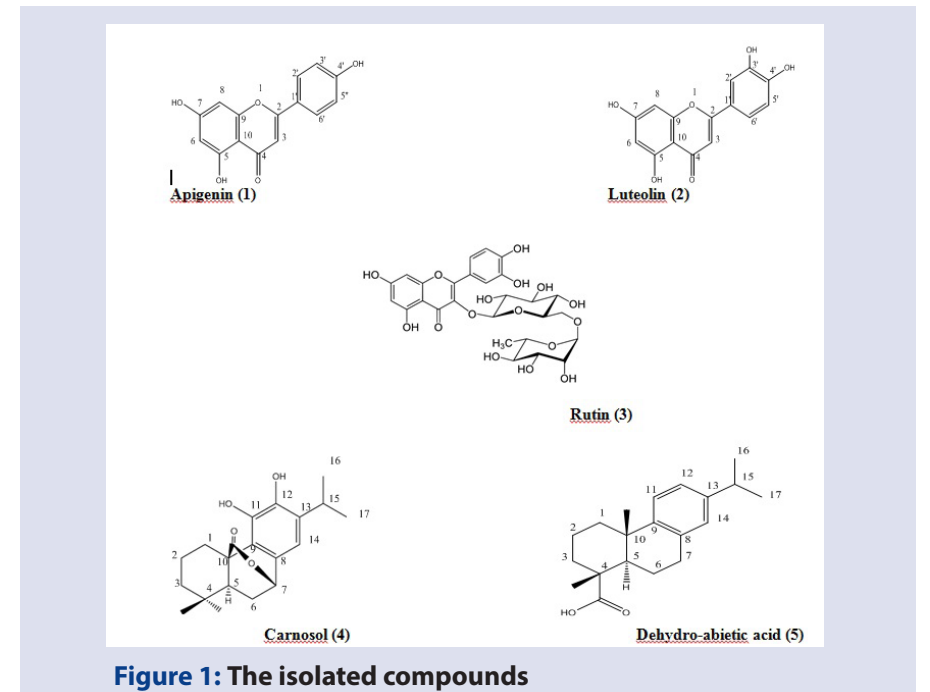


Table 1: ${ }^{1} \mathrm{H}-\mathrm{NMR}$ spectral data of Compound 4

\begin{tabular}{cc}
\hline Position & Material S6 [DMSO] $\delta^{1} \mathbf{H}(\mathrm{Hz})$ \\
\hline $\mathrm{CH}_{2}-1$ & $2.65(2 \mathrm{H}, \mathrm{ddd}, \mathrm{J}=7)$ \\
$\mathrm{CH}_{2}-2$ & $2.09(2 \mathrm{H}$, quintet, J=7 Hz) \\
$\mathrm{CH}_{2}-3$ & $1.25(2 \mathrm{H}, \mathrm{m})$ \\
$\mathrm{H}-5$ & $1.75(\mathrm{lH}, \mathrm{dd})$ \\
$\mathrm{H}-6$ & $2.45(\mathrm{IK} \mathrm{m})$ \\
$\mathrm{H}-7$ & $5.47(1 \mathrm{H} ; \mathrm{d})$ \\
$\mathrm{H}-11$ & - \\
$\mathrm{H}-12$ & $6.67(\mathrm{lH} \mathrm{S})$ \\
$\mathrm{H}-14$ & $3.2(1 \mathrm{H}, \mathrm{heptet} \mathrm{J}=7 \mathrm{~Hz})$ \\
$\mathrm{H}-15$ & $1.14(3 \mathrm{H}, \mathrm{d}, \mathrm{J}=7 \mathrm{~Hz})$ \\
$\mathrm{CH}-16$ & \\
$\mathrm{CH}-17$ & $0.82(3 \mathrm{H}, \mathrm{S})$ \\
$\mathrm{CH} 3-18$ & $0.84(3 \mathrm{H}, \mathrm{S})$ \\
$\mathrm{CH} 3-19$ &
\end{tabular}

Table 2: ${ }^{1} \mathrm{H}-\mathrm{NMR}$ spectral data of Compound 5

\begin{tabular}{cc}
\hline Position & Material S7 [DMSO] $\boldsymbol{\delta}^{1} \mathbf{H}(\mathrm{Hz})$ \\
\hline $\mathrm{CH}_{2}-1$ & $2.18(2 \mathrm{H}, \mathrm{m})$ \\
$\mathrm{CH}_{2}-2$ & $2.8(2 \mathrm{H}$, quintet, J=7 Hz $)$ \\
$\mathrm{CH}_{2}-3$ & $2(2 \mathrm{H}, \mathrm{m})$ \\
$\mathrm{CH}_{-}-5$ & $1.4(1 \mathrm{H}$, triplet $)$ \\
$\mathrm{CH}_{2}-6$ & $1.67(2 \mathrm{H}$, quartet, J=7Hz $)$ \\
$\mathrm{CH}_{2}-7$ & $2.37(2 \mathrm{H}$, triplet, J=7 Hz $)$ \\
$\mathrm{CH}_{-11}$ & $7.17(1 \mathrm{H}, \mathrm{d}, \mathrm{J}=9.1 \mathrm{~Hz})$ \\
$\mathrm{CH}_{-12}$ & $7(1 \mathrm{H}, \mathrm{d}, \mathrm{J}=9 \mathrm{~Hz})$ \\
$\mathrm{CH}_{-14}$ & $6.85(1 \mathrm{H}, \mathrm{S})$ \\
$\mathrm{CH}_{-15}$ & $2.79(2 \mathrm{H}, \mathrm{heptet} . \mathrm{J}=7 \mathrm{~Hz})$ \\
$\mathrm{CH}_{3}-16$ & $1.17(3 \mathrm{H}, \mathrm{d})$ \\
$\mathrm{CH}_{3}-17$ & $1.17(3 \mathrm{H}, \mathrm{d})$ \\
$\mathrm{CH}_{3}-19$ & $1.24(3 \mathrm{H}, \mathrm{S})$ \\
$\mathrm{CH}_{3}-20$ & $1.13(3 \mathrm{H}, \mathrm{S})$ \\
\hline
\end{tabular}

Compound 3 was isolated as yellow powder and was determined to be $\mathrm{C}_{27} \mathrm{H}_{30} \mathrm{O}_{16}$ and was obtained on the basis of ${ }^{1} \mathrm{HNMR},{ }^{13} \mathrm{CNMR}$ and MS analysis. UV spectra of compound 3 in different shift reagents indicated the presence of 5-,7-,3'- and 4'- hydroxyl groups and its UV spectra in $\mathrm{AlCl}_{3}$ and $\mathrm{AlCl}_{3} / \mathrm{HCl}$ showed the absence of 3 '-OH. ${ }^{1} \mathrm{HNMR}$ was integrated for 11 protons and ${ }^{13} \mathrm{CNMR}$ for 27 carbon atoms Moreover, ${ }^{1} \mathrm{HNMR}$ confirmed the presence of protons at positions 2', 5' and 6'. It also showed a doublet a d 6.4 assigned for H-8. The identity of the sugar moiety in " 3 "was determined as rhamnoglucosyl, as showed by the signals in the ${ }^{1} \mathrm{H}-\mathrm{NMR}$ at $\mathrm{d} 5.15(1 \mathrm{H}, \mathrm{d}, \mathrm{J}=2 \mathrm{~Hz})$ and $3.82(1 \mathrm{H}, \mathrm{d}, \mathrm{J}=8 \mathrm{~Hz})$ and their corresponding carbon signals at 100 and 103, respectively in the ${ }^{13} \mathrm{C}-\mathrm{NMR}$ spectra. The signals appearing in the ${ }^{1} \mathrm{H}-\mathrm{NMR}$ at $3.33-3.64$ (m,12 $\mathrm{H}$ of sugar moieties) proved that too. Its ${ }^{1} \mathrm{H}-\mathrm{NMR}$ spectrum displayed the presence of one doublet at $\mathrm{d} 7.52(1 \mathrm{H}, \mathrm{d}, \mathrm{J}=2 \mathrm{~Hz})$ and one singlet at $7.6(1 \mathrm{H}, \mathrm{S})$ for protons at positions 6 ' and 2. ${ }^{13} \mathrm{C}$-NMR showed 27 carbon atoms of which one quaternary carbon atom appeared at $\mathrm{d}$ 178 due to the carbonyl group at position C-4. These spectral data were identical to those reported to rutin "Quercetin 3-O-rutinoside" 18 (Figure 1).
Compound 4 was isolated from the acetone extract of the roots of Salvia libanotica fruticosa in the form of a white crystalline powder, m.p.210$220^{\circ} \mathrm{C}$ and was confirmed to be carnosol through different spectral data. The molecular formula of material 4 was determined as $\mathrm{C}_{20} \mathrm{H}_{26} \mathrm{O}_{4}$ through M.S spectra that showed a molecular peak at $\mathrm{m} / \mathrm{z}=330$ along with ${ }^{13} \mathrm{C}$-NMR that revealed the presence of 20 carbon atoms. ${ }^{1} \mathrm{H}-\mathrm{NMR}$ spectrum of $\mathbf{S 6}$ showed a low field signal at d 6.67 due to proton at position 14. The spectrum also displayed the presence of two singlet signals, each integrated for three protons at 0.82 and 0.84 due to the two angular methyls at positions 18 and 19, respectively. In addition, the spectrum exhibited two proton signals characteristic for an isopropyl group at $\mathrm{d} 1.14$ $(6 \mathrm{H}, \mathrm{d}, \mathrm{J}=7 \mathrm{~Hz})$ and at $\mathrm{d} 3.2(1 \mathrm{H}$, hept, $\mathrm{J}=7 \mathrm{~Hz}) \cdot{ }^{13} \mathrm{C}-\mathrm{NMR}$ showed nineteen resolved signals representing 20 carbons. It displayed the presence of two oxygenated aromatic protons at d 143.5 and 144 due to carbons at 11 and 12 position. In addition, it showed a peak at d 175.95, characteristic for a carbonyl of an ester. Comparing the obtained spectral data with those reported for carnosol, indicated that they are almost identical ${ }^{19}$ (Figure 1 and Table 1).

Compound 5 was also isolated from the acetone extract of the roots of Salvia libanotica fruticosa in the form of a white crystalline powder m.p. $172-175^{\circ} \mathrm{C}$. In the Mass spectrum, the appearance of a peak at $301\left(\mathrm{M}^{+}+1\right)$ established the molecular formula to be $\mathrm{C}_{20} \mathrm{H}_{28} \mathrm{O}_{2} \cdot{ }^{13} \mathrm{C}-\mathrm{NMR}$ showed the presence of six aromatic signals, three of which are quaternary and three are olefinics. In ${ }^{1} \mathrm{H}-\mathrm{NMR}$, the three olefinic protons appeared at $\mathrm{d} 6.85(\mathrm{~s}), 7.00(\mathrm{~d}, \mathrm{~J}=9 \mathrm{~Hz})$, and at $7.17(\mathrm{~d}, \mathrm{~J}=9 \mathrm{~Hz})$ due to protons at positions 14,11 and 12 , respectively. The presence of an isopropyl group was evident through the appearance of a one - proton heptet at $\mathrm{d} 2.79$ $(\mathrm{J}=7 \mathrm{~Hz})$ and a six-proton doublet $(\mathrm{J}=7 \mathrm{~Hz})$ at $\mathrm{d} 1.17 .{ }^{13} \mathrm{C}-\mathrm{NMR}$ spectrum revealed the presence of two methyl signals at $d 16.8$ and 25.2 due to carbons at positions 19 and 20 respectively. Referring to literature, it was found that, all the observed spectral data are similar to those reported for dehydro-abietic acid. ${ }^{20,21}$ Also, it is isolated for the first time from Salvia fruticosa libanotica (Figure 1 and Table 2).

\section{CONCLUSION}

In this work we performed a phytochemical determination of aerial and root parts of Salvia libanotica fruticosa. We isolated the Phenolic diterpenes Carnosol and Dehydro-abietic acid from for the first time from the roots of salvia fruticosa libanotica growing widely in Lebanon and fully assigned for their protons and carbons for the first time too. In addition the flavonoids, luteolin, rutin and apigenin and phenolic acids gallic, rosmarinic acid and ferulic acids were obtained also from aerial parts. All the previously mentioned compounds were responsible for the antioxidant activity of Salvia. ${ }^{22}$

\section{ACKNOWLEDGMENT}

The authors are grateful to Miss F. Mostafa (Department of Pharmaceutical Sciences, Faculty of Pharmacy, AL-Zaytoonah University, Amman, Jordan ) for NMR spectra, MS, IR and UV generated for this study. This work was supported by the Faculty of Pharmacy, Beirut Arab University, Lebanon.

\section{CONFLICT OF INTEREST}

We declare that we have no conflict of interest.

\section{ABBREVIATIONS USED}

NMR: Nuclear magnetic resonance; Ms: Mass spectroscopy; IR: Infra red spectroscopy; UV: Ultra violet; G: Grams; Kg: Kilograms; MHZ: Mega hertz; ${ }^{13} \mathrm{C}$-NMR: Carbon nuclear magnetic resonance; ${ }^{1} \mathrm{H}-\mathrm{NMR}$ : Proton nuclear magnetic resonance; CC: Column chromatography; PTLC: 
Preparative thin layer chromatography; $\mathrm{R}_{\mathrm{f}}$ Rate of flow; MEOH: Methanol; NaOMe: Sodium methoxide; DMSO-d 6 : Deuterated.dimethyl.sulphoxide; HZ: Hertz; m.p: Melting point

\section{REFERENCES}

1. Chehetri D, Parajuli P, Subla G. Antidiabetic plants used by Sikkim and Darjeeling Himalayan tribes. India J Ethnopharmacol. 2005;9:199-202.

2. Elif $\mathrm{C}$ Halis and S PeriganG. Anti-inflammatory effects of different extracts from three Salvia species, Turky. J Bot. 2012;36:59-64.

3. Aboul-Ela M. New Abietane Diterpene Quinone Fatty Acid Esters from Salvia Lanigera, Alex. J Pharm Sci. 2006:20(1):32-4.

4. Mayer B, Baggio CH, Freitas C, Santos AC, Twardowschy A, Horst H, Pizzolatti MG, Micke GA, Heller M, Santos E, FleithOtuk M, and Marques MCA. Gastroprotective constituents of Salvia officinalis L. Fitoterapia. 2009;80:421-426.

5. Rizk A, El-Ghazaly G. Medicinal and Poisonous Plants of Qatar. Science and Applied Research Centre. University of Qatar King print of Richmond. 1995;140-1.

6. Aboul-Ela M. Aegyptinone D. A New Rearranged Abietane Diterpene-p-quinone from Roots of Salvia aegyptiaca L. growing in Egypt. Alex J Pharm Sci. 2006;20(1):29-31.

7. Norlaily MA, Swee KY, Wan WH, Boon KB, Sheau WT, and Soon GT. The promising future of Chia Salvia hispanica. J Biomed Biotechnol. 2012; Artticle ID 171956, 9 pages.

8. Li M, Zhang J, Ye Y, Fang J. Constituents of the roots of Salvia prionitis. J Nat Prod. 2000;63:139-41.

9. Aboul-Ela M, Soad MT, Nagwa S, El-Lakany MA. (2002). Minor Diterpenoids from the roots of Salvia lanigera growing in Egypt, Alex J Pharm Sci. 2002;16(2):139-43

10. Aboul-Ela M, and El-Lakany MA. Abietane diterpenes from the roots of Salvia lanigera. Alex J Pharm Sci. 2000;14(1):57-61.
11. Jimenez ME, Portugal EM, Lira-Rocha A, Soriano-Garcia M, and Toscano RA. A new royleanone-type diterpene from Salvia sessei. J Nat Prod. 1998;51 (2):2438

12. El-Lakany MA. New Rearranged Abietane Diterpenoids from the Roots of Salvia Aegyptiaca L.Growing in Egypt. Natural Product Sciences. 2003;9(4):220-2.

13. El-Lakany MA. Two new diterpene quinones from the roots of Salvia Lanigera Poire. Pharmazie. 2003:58:75-6.

14. Raafat K, Boukhary R, Aboul-Ela M, El-Lakany MA. Endogenous Lebanese Plants Treating Diabetes and Related Complications. Nat Prod Chem Re. 2013;1:112-20.

15. ZhyY Ni, Quing-Wen Shi, Mei D, Hiromasa K, Yu Cheng Gu, Bin cong Constituents from Salvia species and their biological activities. Chemical Reviews. 2012;112(11):5967-602.

16. Matloubi MF, Moghddam M, Moridi F, Taheri S, Tafazoli M, Amin G. Chemical constituents from Salvia macrosiph. Chemistry of Natural Compounds. 2008;44(4).

17. Payán-Gomez et al. Computational molecular characterization of the Flavonoid rutin. Chemistry Cental J. 2010;4:12

18. Bauer J, Kuehnl S, Rollinger JM, Scherer O, Northoff H, Stuppner H, et al. Carnosol and carnosic acids from Salvia officinalis inhibit microsomal prostaglandin E2 synthase-1. J Pharmacol Exp Ther. 2012;342(1):169-76.

19. Ufuk K, IsI H, Mehmet O, Fevz O, Gulact T, Ayhan U. Antioxidant and anticholinesterase constituents of Salvia poculata. Turk J Chem. 2009;33:813- 23.

20. Yu Ni, Quing-Wen Shi, Mei D, Hiromasa K, Yu-Cheng Gu. Constituents from Salvia species and their biological activitie. Chemical Reviews. 2012;112(11):5967602 .

21. Boukhary R, Raafat K, Ghoneim A, Aboul-Ela M, El-Lakany AM. Anti-Inflammatory and Antioxidant Activities of Salvia fruticosa: An HPLC Determination of Phenolic Contents. Evidence-Based Complementary and Alternative Medicine 2016 Article ID 7178105, 6 pages.

\section{GRAPHICAL ABSTRACT}

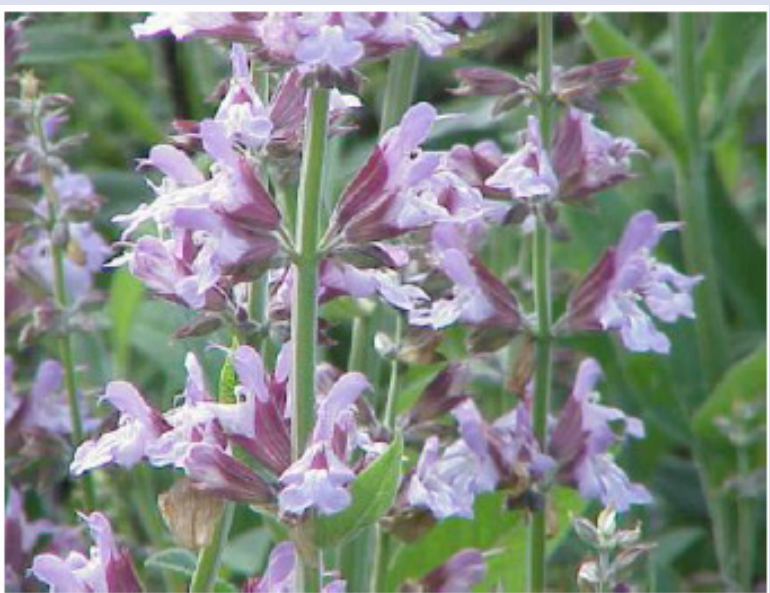

\section{SUMMARY}

Isolation of eight phenolic materials from Salvia fruticosa libanotica providing a proof about the wide use of this plant in folk medicine as antidiabetic, anti-oxidant and in the cure of many illness.

\section{Salvia fruticosa libanotica}

Cite this article: Boukhary R, Aboul-EIA M, Al-Hanbali O and El-Lakany A. Chemical Constituents from Salvia fruticosa libanotica. Pharmacog J. 2018;10(1):45-8. 